\title{
Answer to comment on "sleep quality, arousal and pain thresholds in migraineurs: a blinded controlled polysomnographic study"
}

\author{
Morten Engstrøm ${ }^{1,2^{*}}$, Knut Hagen ${ }^{1,3}$, Marte Bjørk ${ }^{4,5}$ and Trond Sand ${ }^{1,2}$
}

\begin{abstract}
We discuss the comments on our article "Sleep quality, arousal and pain thresholds in migraineurs. A blinded controlled polysomnographic study" published in JHP 2013 Feb 14;14(1):12. We hypothesize that migraineurs need more sleep than healthy controls and more sleep than they manage to achieve. Some migraineurs probably have a decreased ability to process incoming stimuli. Increased spontaneous pain may follow either sleep restriction or sleep disturbance. A comparison of migraineurs with attack onset related to sleep, migraineurs with attack onset not related to sleep and controls will be reported in another paper.
\end{abstract}

Keywords: Migraine; Sleep; Sleep deprivation; Arousal; Pain

Sir,

We thank the group at Institute of Neurology, Catholic University in Rome for the comments [1] on our article [2]. We are delighted to get this opportunity to improve and clarify the interpretation of our findings. It is especially gratifying to answer comments from this group as the publication from 2006 "Dysfunction of arousal system in sleep-related migraine without aura" by Della Marca et al. [3] has been an important and inspiring article during our work with this project.

In our study the migraineurs reported normal sleep times and increased daytime tiredness while we found polysomnographic signs indicating foregoing sleep deprivation. We therefore hypothesized that migraineurs need more sleep than healthy controls and more sleep than they manage to achieve. The relevance of sleep deprivation in migraineurs is amplified by signs of even stronger sleep pressure in the early migraine phase as reduced latency to sleep onset was present.

Both reduced and increased sleep and change in sleep pattern are reported as migraine triggers [4-7]. Even small delays in bedtime can probably release an attack if

\footnotetext{
* Correspondence: morten.engstrom@ntnu.no

'Department of Clinical Neurosciences, PB 8905, MTFS, Norwegian University of Science and Technology, Trondheim N-7489, Norway

${ }^{2}$ Department of Neurology and Clinical Neurophysiology, St. Olavs Hospital, Trondheim N-7006, Norway

Full list of author information is available at the end of the article
}

the need for sleep is increased. Long sleep is not the most frequently reported migraine trigger and the importance of long sleep itself might be questioned as weekend migraine seems infrequent [8]. To speculate, long sleep periods are probably associated with increased sleep depth which itself seems to be a risk factor for migraine $[2,9]$. Furthermore, a period of planned sleep restriction most likely is less stress- and harmful than repeated and irregular disturbances during sleep, at least when total sleep time are equal. Repeated disturbances tend to increase light sleep while sleep restriction will increase the more restful slow wave sleep [10]. However, sleep restriction or -deprivation also increase arousal thresholds and thereby also the seriousness of respiratory disturbances [11]. This reasoning is consistent with the notion that arousals are a part of homeostatic adaptive response. High levels of (fast) arousals are probably constitutional or related to repeated occasional disturbances (of variable etiology) during sleep. After a disturbed night the sleep depth and arousal threshold tend to increase [11]. Consequently increased sleep pressure might increase the sleep quality per se but also make one more susceptible to respiratory disturbances and latent sleep apnea. It is therefore difficult to evaluate differences in pain related to sleep disturbance versus sleep restriction. However, there are reports indicating 
increased spontaneous pain after sleep restriction [12-14] and also after sleep disturbance [10].

Sleep deprivation also reduce the ability to process incoming stimuli manifested by increased pain sensitivity and consistent with reported increased-, skin-, light noise-, smell sensitivity and testing of pain thresholds among migraineurs [15-21]. However, it is uncertain if affected migraineurs are able to recover and normalize arousal levels whether insomnia is present or not. Reasonable treatment most likely should aim at not making things worse. So bottom line we think some migraineurs have reduced ability to process incoming stimuli, but to us it seems that this reduction is related to a sleepdeprived state. However, another constitutional "sleepdeprived phenotype" with some characteristics similar to narcoleptic patients in sleep [1] is possible.

In our study we did not perform CAP- scoring, but alternatively scored D- and K-bursts similar to CAP A1 bursts [22]. We intend to report results for migraineurs with attack onset related to sleep (sleep migraine) and compare them with migraineurs with attack onset not related to sleep and controls in another submitted paper. We will there also comment on slow bursts, the reported apparent paradoxical finding of reduced arousal- and increased awakening index found in the migraineurs described in our published paper in JHP [2].

\section{Abbreviation}

CAP: Cyclic alternating pattern

\section{Competing interests}

The authors have no competing interest to disclose.

\section{Authors' contributions}

ME prepared the drafts of this letter. TS has revised several drafts. MB and $\mathrm{KH}$ have revised the final version. All authors read and approved the final manuscript.

\section{Author details}

${ }^{1}$ Department of Clinical Neurosciences, PB 8905, MTFS, Norwegian University of Science and Technology, Trondheim N-7489, Norway. ${ }^{2}$ Department of Neurology and Clinical Neurophysiology, St. Olavs Hospital, Trondheim N-7006, Norway. ${ }^{3}$ Norwegian National Headache Centre, St. Olavs Hospital, Trondheim N-7006, Norway. ${ }^{4}$ Department of Neurology, Haukeland University Hospital, Bergen N-5021, Norway. ${ }^{5}$ Department of Clinical Medicine, University of Bergen, Bergen N-5021, Norway.

Received: 29 May 2013 Accepted: 25 June 2013

Published: 1 July 2013

\section{References}

1. Vollono C, Testani E, Losurdo A, Mazza S, Della Marca G (2013) Migraine, arousal and sleep deprivation: comment on: "sleep quality, arousal and pain thresholds in migraineurs: a blinded controlled polysomnographic study". $J$ Headache Pain 14(1):50

2. Engstrom M, Hagen K, Bjork MH, Stovner LJ, Gravdahl GB, Stjern M, Sand T (2013) Sleep quality, arousal and pain thresholds in migraineurs: a blinded controlled polysomnographic study. J Headache Pain 14(1):12

3. Della Marca G, Vollono C, Rubino M, Di Trapani G, Mariotti P, Tonali PA (2006) Dysfunction of arousal systems in sleep-related migraine without aura. Cephalalgia 26(7):857-864

4. Andress-Rothrock D, King W, Rothrock J (2010) An analysis of migraine triggers in a clinic-based population. Headache 50(8):1366-1370
5. Hauge AW, Kirchmann M, Olesen J (2011) Characterization of consistent triggers of migraine with aura. Cephalalgia 31(4):416-438

6. Kelman $L$ (2007) The triggers or precipitants of the acute migraine attack Cephalalgia 27(5):394-402

7. Martin PR (2010) Behavioral management of migraine headache triggers: learning to cope with triggers. Curr Pain Headache Rep 14(3):221-227

8. Alstadhaug KB, Salvesen R, Bekkelund S (2007) Weekend migraine. Cephalalgia 27(4):343-346

9. Houle TT, Butschek RA, Turner DP, Smitherman TA, Rains JC, Penzien DB (2012) Stress and sleep duration predict headache severity in chronic headache sufferers. Pain 153(12):2432-2440

10. Smith MT, Edwards RR, McCann UD, Haythornthwaite JA (2007) The effects of sleep deprivation on pain inhibition and spontaneous pain in women Sleep 30(4):494-505

11. Bonnet MH, Doghramji K, Roehrs T, Stepanski EJ, Sheldon SH, Walters AS, Wise M, Chesson AL Jr (2007) The scoring of arousal in sleep: reliability, validity, and alternatives. J Clin Sleep Med 3(2):133-145

12. Haack M, Mullington JM (2005) Sustained sleep restriction reduces emotional and physical well-being. Pain 119(1-3):56-64

13. Haack M, Lee E, Cohen DA, Mullington JM (2009) Activation of the prostaglandin system in response to sleep loss in healthy humans: potential mediator of increased spontaneous pain. Pain 145(1-2):136-141

14. Kundermann B, Spernal J, Huber MT, Krieg JC, Lautenbacher S (2004) Sleep deprivation affects thermal pain thresholds but not somatosensory thresholds in healthy volunteers. Psychosom Med 66(6):932-937

15. Schwedt TJ, Krauss MJ, Frey K, Gereau RW (2011) Episodic and chronic migraineurs are hypersensitive to thermal stimuli between migraine attacks. Cephalalgia 31(1):6-12

16. Sand T, Zhitniy N, Nilsen KB, Helde G, Hagen K, Stovner $\sqcup$ (2008) Thermal pain thresholds are decreased in the migraine preattack phase. Eur J Neurol 15(11):1199-1205

17. Burstein R, Cutrer MF, Yarnitsky D (2000) The development of cutaneous allodynia during a migraine attack clinical evidence for the sequential recruitment of spinal and supraspinal nociceptive neurons in migraine. Brain 123(Pt 8):1703-1709

18. Zappaterra M, Guerzoni S, Cainazzo MM, Ferrari A, Pini LA (2011) Basal cutaneous pain threshold in headache patients. J Headache Pain 12(3):303-310

19. Bigal ME, Ashina S, Burstein R, Reed ML, Buse D, Serrano D, Lipton RB, Group A (2008) Prevalence and characteristics of allodynia in headache sufferers: a population study. Neurology 70(17):1525-1533

20. Lovati C, D'Amico D, Bertora P, Raimondi E, Rosa S, Zardoni M, Bussone G, Mariani C (2010) Correlation between presence of allodynia and sleep quality in migraineurs. Neurol Sci 31(Suppl 1):S155-S158

21. Olesen J (2004) The international classification of headache disorders: 2 nd edition, vol 24 suppl 1. Cephalalgia 24:9-160, 2004/02/26 edn

22. Terzano MG, Parrino L, Smerieri A, Chervin R, Chokroverty S, Guilleminault C, Hirshkowitz M, Mahowald M, Moldofsky H, Rosa A, Thomas R, Walters A (2002) Atlas, rules, and recording techniques for the scoring of cyclic alternating pattern (CAP) in human sleep. Sleep Med 3(2):187-199

doi:10.1186/1129-2377-14-56

Cite this article as: Engstrøm et al:: Answer to comment on "sleep quality, arousal and pain thresholds in migraineurs: a blinded controlled polysomnographic study". The Journal of Headache and Pain 2013 14:56.

\section{Submit your manuscript to a SpringerOpen ${ }^{\circ}$ journal and benefit from:}

- Convenient online submission

- Rigorous peer review

- Immediate publication on acceptance

- Open access: articles freely available online

- High visibility within the field

- Retaining the copyright to your article

Submit your next manuscript at $>$ springeropen.com 